\title{
The Role of Technology Transfer in Supporting Climate Change Adaptation the Avenue to Disaster Risk Reduction in the Arid and Semiarid Zones
}

\author{
Jamal Alrusheidat ${ }^{1 *}$ and Wafa'a Abu Hammour ${ }^{2}$ \\ ${ }^{1}$ Jerash University, Amman, Jordan \\ ${ }^{2}$ National Center for Agricultural Research and Extension (NCARE). Amman, Jordan
}

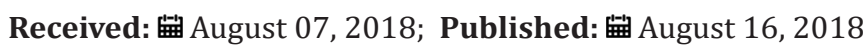

*Corresponding author: Jamal Alrusheidat, Jerash University, Amman, Jordan

\begin{abstract}
No doubt that climatic development and related changes are not new, bur a worldwide phenomenon that never respected national boundaries. Their severe consequences and negative impacts have touched most world countries; melting glaciers, deadly typhoons, catastrophic hurricanes, brutal tornadoes, torrential rains, harsh drought, continuous heat waves heavier precipitation, frost, fluctuation of annual average temperatures, changing duration, shifting seasons and disastrous floods are just a few of the many forms of climate change consequences. There is no single world country that was not seriously devastated by economic, health, social and or environmental complications. All these shattering consequences have urged most countries around the globe to find mitigation measures, adaptation techniques and methods and put this goal as a top priority of international conferences and symposiums at the local, regional and international levels. The notion "Act locally and think globally" has become the main slogan for a collective action to ease the consequences of the climate change. Needless to say, that huge efforts in awareness raising, education, training, technology transfer and information use can make a big difference, which have immense potentials to mitigate the implications of climate change. It is in fact the only hope to face the negative impacts of climate change.
\end{abstract}

Keywords: Climate Change; Technology Transfer; Adaptation; Mitigation

\section{Introduction}

Climate change, as mentioned earlier, is an intricate global environmental dilemma, which is unpredictable, controversial and a never-ending predicament. It affects every single person on earth and creature living on our planet. The fact that cannot be denied is that the intricacy of the climate change dilemma lies in the absent of appropriate understanding and/or justification of the reasons behind its complications and developments. Hence, its worldwide excessive impact, unpredictability, accelerating trends, tremendous extreme influence, continuity and increasing complexity make the situation even worse.

For decades, climate change implications have been affecting not only agriculture, but also the economy, tourism, health, as well as social and environmental aspects. Definitely, climate change implications and their accelerating pace, combined with increased global population and income growth will affect the overall food situation [1]. Among the negative influence of climate change on agriculture is the low yield and the bad quality of agricultural products, which is obvious on all crops. Nobody doubt the fact that the agricultural sector is the most affected by climate change implications among all other sectors. Indeed, the sector is facing enormous challenges, where extreme weather conditions and events threaten the existence of humanity. The existence of new insects, diseases and weeds, combined with shifting seasons and shortening the growing seasons are among the most serious upshots that we are witnessing daily. Within this context, it is obvious that technology transfer is one of the best solutions to the problem, where a growing recognition of its potential role as a major response is increasing. With this fact agrees [2], where indicated that mitigating climate change requires information, education, and technology transfer. It is urgently needed by resource scarce smallholders, who are the most affected by climate change, yet, they contribute very little to the problem. 
It is recognized worldwide that adaptation and mitigation are the main two major areas needed by farmers to mitigate the impact. For sure, diminishing the global climate change impacts necessitate vast scientific knowledge, massive financial resources, enormous physical capacities, huge logistical infrastructure, as well as big technical and human resources. Today, more than ever before, immense efforts and substantial awareness and attitude change are needed urgently not only for Developing Countries but Developed Countries as well. Hence, serious collective efforts are needed by policy and decision makers, scientists of all fields, academia, farm owners and farmers as well as all ordinary citizens. Although huge efforts were made by scientists, but many still believe that there is no quick and instant solution to the problem and no universal remedy or a silver bullet that can stop, freeze, limit or at least decrease the climate change impacts. What can ease the problem is simply enforcing rules and regulations, policies and recommendations parallel with reliance on technology transfer. Definitely, determination and dedication are also of paramount importance when financial and technical resources are available. Certainly, reliance on generous regional and international support and technical assistance are of great importance.

\section{Worldwide Shocking Information}

According to the World Bank [3], Asia is the most vulnerable continent on earth. The report indicated that in 2009 , over $60 \%$ of Asian countries were affected by property damage from severe natural disasters. The report also pointed out that since 1997, over $82 \%$ of all lives lost in disasters were in Asian countries. These countries sustained the heaviest mortality rate from catastrophic events related to climate change. In Asia, also six out of ten of the most vulnerable cities in terms of exposed population. No doubt that the magnitude of the problem, specifically in Asian countries, is immeasurable. For an example, if no measures are considered in Bangladesh, the expected damage from a single severe cyclone increase fivefold to reach $\$ 9$ billion by 2050 . The same applies for Vietnam's Mekong River Delta, where the sea level will rise 30 $\mathrm{cm}$ by 2050. For an example, a reduction of rice production by 13 percent will occur when an increased deluge and salinity happen, when over 300 thousand ha will be out of business. China, Vietnam, Laos, The Philippines, Bangladesh, and many other countries are no exception. About 130 million people are living along the coast in low lying islands in China and facing unpredictable destiny due to the enormous threat of cyclones and typhoons. 40 million in Vietnam are expected to face the same danger. Generally speaking, the poorest households are the most affected by the climate change disasters [3]. According to the same source, 12 billion dollars were the cost of the damaged lands, cities, river banks, etc. in the last three decades alone, in the Middle East, and specifically in the Arab world, temperatures are projected to rise 3-4 degrees Celsius by the end on this century. The warmest year since 1800's was 2010-11, when heat wave records began [4] Indicated that heat waves with maximum temperatures are very likely to become more frequent. Drier and hotter conditions will cause fires to increase in scrub and forest in Maghreb and eastern Mediterranean areas 19 countries in the Middle east, including five Arab countries, set a new high record. for an example, the temperature reached 53.5 degrees in Kuwait, but expected to increase to 75 percent by 2050. This shows that three out of four people might be affected in a way or another in the Arab world [5] other forms of climate change will include, but not limited to, an increase in severe weather events, such as droughts and floods and greater seasonal temperature variability.

The report, which was produced in partnership with the League of Arab States (LAS), warns that climate change implications pose a big threat and a big challenge to the development goals of the millennium. Jordan, for an example, the second poor country in the world in terms of water resources will face food insecurity and water insecurity due to sharp rainfall decrease with temperature increase compounded with a growing population. According to Dorte Verner, the Climate Change Coordinator for the Middle East and North Africa at the World Bank, who gave an alarming signal to the situation that the whole region will face an increased demands for fresh water by $16-50 \%$ by 2050 and a $10 \%$ decrease in rainfalls and the indicated that between 1980 and 2008 over 37 million Arab people were affected and more than 20 billion dollars were lost due to natural disasters [4]. Overt 55 million people are affected annually by climate related disasters and the estimated damage was $\$ 789$ billion dollars. In Asia, about the same number of people are affected annually by floods (57 million people), where around $86 \%$ of the reported damages are climate-related disasters. At the global level, 142 million people are affected annually by natural disasters, of which 139 million people were affected by climate related disasters. It is obvious from the facts mentioned above that Asia and the Pacific, are the most affected by climate related disasters. $70 \%$ of these countries are vulnerable to climate change and disasters according to the UNU. Countries such as Vanuatu, Tonga, Philippines, Solomon Islands, Bangladesh, Timor-Leste, and Cambodia are the most vulnerable countries in Asia and the Pacific. The fact that cannot be denied is that agriculture, fisheries and forestry are the main sectors affected by climate related disasters, where $60 \%$ of the people depend largely on these sectors for find living. The real cost of the damage has sky-rocketing numbers. Between 600 billion to 1.5 trillion USD annually are needed to help these countries. By 2025, The bank estimated that floods in these countries will be threatening between 300 and 410 million people< In some Pacific Islands, it is even much higher, 245-341 million people.

\section{The Scary Status}

According to a report published by Karas J [6], it was pointed out that the Mediterranean basin is not immune to the climate change implications. Most North African and Eastern Mediterranean 
countries are the most to suffer from serious impacts of the climate change combined with the desertification problems. At the same time, the annual precipitation is projected to decline by $10-40 \%$. Temperatures could rise by over $4{ }^{\circ} \mathrm{C}$ by the beginning of the next century. On the other hand, the report also indicated that the Mediterranean Sea levels could rise by $1 \mathrm{~m}$ by 2100 due to melting glaciers and oceans' expansion. As a result, rivers would become saltier. Egypt, Italy and Greece could have the worst consequences, specifically the Nile Delta, Venice and Thessaloniki respectively, Sand storms and reduction in vegetation cover in northern Sahara and Peri desert region will be increasing soil erosion, hence most Arab countries will have to deal with not traditional environmental threats, but severe, complicated, continuous and spreading complications. Water scarcity will be so severe to the extent that countries will fight each other over water. Some other problems, such as biodiversity loss, desertification, pollution of marine and coastal areas, air pollution and many others will be very common.

The Persian Gulf region is no exception. All six countries of the council (GCC); Saudi Arabia, United Arab Emirates (UAE), Bahrain, Kuwait, Oman and Qatar are subject to suffer significant ramifications from global warming. Bahrain and Qatar, where most population live less than 5 meters above sea level are especially susceptible to inland flooding due to the small land mass that is in danger of being inundated as sea levels rise, Saudi Arabia, Oman and the UAE are also rated "highly" vulnerable. Other countries of the Middle East like Yemen, Jordan, Lebanon, Libya and Tunisia are ranked among "extremely" vulnerable countries and score "high" on the CCI index [7].

\section{Water Crisis, Rising Temperatures, etc.}

Most of the Arid and Semiarid Zones are suffering from a chronic and even disastrous water problem. In Jordan, for an example, the average per capita use is lower than any other country in the world. It reaches 145 cubic meters per capita per year, a very low number by all standards, if we take into consideration that the United Nations classified countries with less than 500 cubic meters per person per year as having an "absolute scarcity" of water [8]. Karas J [6] regarding the increase of water shortages and decline in water quality, pointed out that the first climate change impacts will be felt first in the Mediterranean water resource system, where reductions in water availability would hit southern Mediterranean countries the hardest. Countries like Morocco, Algeria, Tunisia, Libya, Egypt, Syria, Malta and the Lebanon will be the most affected by the shortages and some water supplies could become unusable due to salt penetration into rivers and coastal aquifers as sea level rises combined with water pollution which become more concentrated with reductions in river flow, hence causing major health hazard in the region. Karas J [6] also stated that across the Mediterranean region, yields of cereals and other crops could decrease substantially due to the increased frequency of drought, land losses through desertification, increased competition for water and prevalence of pests and diseases. On the other hand, by 2050 or earlier, North Africa and the Near East could witness the disappearance of most of the steppe rangeland and its transformation to desert. Food security could be also threatened by the sharp fall in production, world prices for many commodities such as maize, wheat, soybean and poultry could rise significantly as a result of global climate changes. Livestock production would suffer due to deterioration in the quality of rangeland. The magnitude is so immense in most countries to the extent that Egypt, for example, might lose agricultural production over an area extending $20 \mathrm{~km}$ inland. In Tunisia, rising temperatures could lead to the disappearance of nationally important fisheries, the loss of all food plants and breeding waterfowl. The reductions in food and fiber will cause malnutrition and hunger for millions of people. Water shortages as well as damaged infrastructures would increase the risk of cholera, malaria and dysentery, while the combination of heat and pollution would increase the risk of respiratory illnesses, extent of infectious diseases, dengue fever, while extreme weather events could increase death and injury rates. Several valuable ecosystems could be lost, wetland area will face the threat of drying out. Other countries are not immune, where a 3 to $4^{\circ} \mathrm{C}$ rise in temperatures will cause up to $85 \%$ of wetland sites in southern Europe to disappear.

Not only Mediterranean countries loose substantially in economic terms, the human and economic costs of desertification increase would be tremendous. The annual costs of desertification for Tunisia and Spain alone are $\$ 100$ and $\$ 200$ million respectively. The magnitude of the climate change from the economic point of view is so immense to the extent that another World Bank study predicted that \$75-100 billion a year, is the amount needed to adapt to an approximately $2^{\circ} \mathrm{C}$ warmer world by 2050. Definitely, Asian and Pacific countries will bear most of the cost. No doubt that those poorer developing countries are affected excessively, and more vulnerable than other countries to climate change implications, and they are greatly devastated from the impacts of natural disasters. This is due to a number of reasons. Probably their reliance on climate sensitive sectors, particularly agriculture, their poor infrastructure, geographic exposure to disasters, low incomes and most importantly, their inability to stand firmly against disasters because of lack of expertise, are the most serious factors.

Another frightening number was reported by IFRC and CRED [9]. It indicated that, between 1990 -1999, around 200 climate related disasters strike per year. Ten years later, around 350 climate related disasters on average per year happened. This is an increase of about 75 percent from previous decade. During these years, and according to the Asian Development Bank [10] the climate related disasters affected more than 200 million people in Asian and the Pacific countries, which compose about 90 percent of world population affected by disasters. Within two years, and 
specifically during 2010-2011, around 42 million people were displaced from extreme weather events. According to Nelson G et al. [1], agriculture is the most vulnerable sector to climate change. According to the same source, in 2005, over 50 percent of the economically active population in developing countries, which is close to 2.5 billion people, relied on agriculture as the main source for their livelihoods. Today, this number has increased dramatically, where three out of four people of the world's poor live in rural areas. The magnitude is so immense to the extent that at least $\$ 7$ billion in additional funds annually are needed to finance investments in research, rural infrastructure and irrigation, to offset the negative effects of climate change on human wellbeing. More bad news of the climate change implications. Madhava S and Durwood Z [11], for an example, believe that Developing Countries will need about $\$ 200$ billion annually by 2030 to bring about a 25 percent reduction in global greenhouse gas emissions. No doubts that the lives of the poorest and most venerable people are the most to be affected by the climate change implications.

\section{Severe Consequences}

Since climate change is a worldwide phenomenon, it is believed that most world countries will suffer in a way or another. At the global level, the magnitude of the effect is various and immense to the extent that an increase of just $2{ }^{\circ} \mathrm{C}$ in the average temperature will reduce world GDP by about $1 \%$ as Stern [12] predicted. This is a huge impact if we take into considerations the trillions of dollars around the world that are circulating every year. Another prediction of how immense the climate change is [13] stated, agreed and supported the notion that the impact of the climate change is substantial. For an example, India and Africa will face reductions of agricultural output by 30 percent or more. As Nelson G et al. [1] pointed out, agriculture, is extremely vulnerable to climate change [1]. They stated that in 2005, over half of the population in Developing Countries, which was estimated at 2.5 billion, relied on agriculture for their livelihoods. Nowadays, according to the World Bank [14], around 75 percent of world's poor live in rural areas and they are the most affected. According to a Food Policy Report, agriculture and human wellbeing will be severely affected by one or more of the following climate change implications; yield reduction, price increase, decline of meat consumption, imbalance of supply and demand, declining calorie availability, higher feed prices for livestock, increase malnutrition and lower investments. As a result, increase in death rates, unemployment will soar, and social instability will be in jeopardy. The agricultural sector in particular will be subject to some or all of the following implications due to the climate change; appearance of new diseases, insects or weeds not known before in the area, shortening growing seasons, not completely ripen veggies or fruits with less vitamins, minerals or other crucial ingredients.

Developing countries, as most researchers and analysts predict, are the most to be affected, and specifically, South Asia, which will be particularly hard hit by climate change implications. The fact that cannot be denied is that the yield for the most important crops will decline sharply due to the shifting seasons, rainfall variations, shortening of seasons, higher temperatures, frequent frost and weed and pest proliferation. In light of all these complex developments that the world is facing, especially, Developing Countries, scientists have no doubts that Developing Countries are more vulnerable to climate change, and they will have less suitable climates for agricultural practices. Most of these countries depend largely on agriculture, they lack proper and adequate financial resources, have weak infrastructure to respond properly to increased variability and most importantly, they are facing all the implications of the climate change alone. Definitely, rainfed areas as well as irrigated regions will have varying effects on yields, specifically irrigated crops in South Asia, which will experience large declines. It is well known that when yields of the most important agricultural crops (rice, wheat soybeans, maize, etc.) are affected, prices increase. As a result, higher feed prices will result in higher meat prices, hence causing the reduction of the growth in meat consumption. Among the consequences that the sector is facing is the higher temperatures, which eventually reduce yields of most crops while encouraging pest and weed proliferation. The fact that the changes in precipitation patterns, despite few gains in some crops in some regions of the world, will show an increase of the likelihood of short run crop failures and long-run production will decline. Most researchers, analysts and environmentalists believe that the overall impact of climate change on agriculture is expected to be negative, and as a result, global food security is threatened.

The overall impact of climate change is unpredictable; however, malnutrition will be a case that most developing countries will have to face. According to Nelson G et al. [1] the 2050 will witness lower calorie availability than in the no climate change scenario. The decline will be even lower to 2000 levels throughout the developing world. By the same year, the decline in calorie availability will increase child malnutrition by at least 20 percent comparing to a world with no climate change impact. Based on the mentioned facts, the climate change will eliminate a great deal of the improvement in child malnourishment levels that would occur with no climate change. Thus, huge amounts of financial resources are needed to cope with the various negative impact of the climate change. For an example, the large agricultural productivity investments of about USD 7.1-7.3 billion are urgently needed more than ever before to raise calorie consumption enough to offset the negative impacts of climate change on the health and well-being of children [1].

\section{The Solution Technology Transfer Can Make the Difference}

Certainly, technology transfer will never be able to solve the whole problem of the climate change implications, but definitely it can make a big difference. There are a number of recommendations 
that were suggested by the Food Policy Report, presented by IFRPI [1] which give a high concern for a number of measures to combat the negative impact of the climate change. Technology transfer was among the main parts of the recommendations. The group of scientists and scholars gave technology transfer a crucial role in the adaptation process. They include reviving national research and extension programs in each country. The recommendations call for heavy investments in laboratory scientists and infrastructure as well as partnerships with other national and international centers. The important aspect in the recommendations urge for a strong collaboration with local farmers, traders, input suppliers, consumer groups and other stakeholders as an essential and effective measures for the development and dissemination of appropriate, cost-effective techniques that will help strengthen communication among all involved groups (scientists, extension agents, farmers, etc. to meet the challenges of climate change.

Another vital recommendation of the report calls for agricultural adaptation as a key agenda point in international climate meetings, conferences and symposiums. This should allow governments and other organizations to advance proposals for practical actions on adaptation in agriculture. The report also advocates for the recognition of enhanced food security as a major partner of climate change adaptation. Needless to say, that climate change will pose huge challenges to food security efforts and any activity in the direction of supporting agricultural adaptation will definitely enhance food security. The increased food security measures will assist the rural poor with the needed resources that will help them adapt to climate change. Supporting communitybased adaptation strategies are also of great importance. The need is urgent for national and international development agencies to ensure that all financial, technical as well as capacity-building measures target local communities. Community participation in the national adaptation planning processes is a must. Community-based adaptation strategies can make all the difference in assisting rural communities strengthen their capacities to cope with disasters. Such groups are encouraged to diversify their livelihoods, improve land-management skills, coordinate with all involved partners and fully adapt national policies and strategies.

Another crucial factor that must be considered is the increase of funding for adaptation programs. It is estimated, according to the same report, that at least seven billion dollars are needed per year. Another seven billion dollars per year are also required to finance rural infrastructure, research and irrigation systems to offset the negative implications of climate change on human wellbeing. Extension programs can play a strategic role in information sharing through the transfer of new technologies and techniques, capacity building, teaching improved management systems; facilitate cooperation and interaction and encouraging the establishment of farmers' networks. Specific services to mitigate climate change should include, but not limited to, disseminating local cultivars of drought-resistant crop varieties, improve global data collection, dissemination, and their analysis. Any global efforts to collect and disseminate data among all involved parties must be strengthened. The fact that cannot be denied is that successful development and the effective diffusion of the latest technologies in agriculture will shape the way farmers mitigate and adapt to climate change. Certainly, regular and continuous observations of unusual events are of paramount importance. They must be recorded, analyzed, disseminated and considered. If technology transfer is to be successful, then it must meet local needs and priorities. Willingness of the people to understand the new developments, act, make the desired change needed and create a difference are important to consider. Without doubt, when priorities are set, economic and physical capabilities are convened, and social and psychological conditions are regarded, then the impact of technology transfer can be doubled.

In reality, and in order to speed TT, the six factors (categories); economic social, environmental, political, perception and attitudes, and regulatory factors are all of immense importance. None of the above factors are less or more important than the others and neither can be ignored nor eliminated. Funds are needed to support education, Research and Development (R\&D), extension and purchase of technologies. On the other hand, social factors are prerequisite for a successful technology transfer process. This can speed, slow and even stop the process the more a nation is open to the world, the faster the technology transfer can be disseminated, especially if they don't stand against the culture, norms and traditions. Political aspects are seen and noticed in faster TT. Completely unwanted results might be seen if they are ignored [15]. Meeting the needs and priorities of the local people must have high level of acceptance, active participation as well as strong willingness to adopt, otherwise all the efforts are in jeopardy.

\section{Concluding remarks}

a. Huge financial support, social participation and interaction, political interference, environmental awareness, strong involvement by policy responses as well as a new set of policy instruments for decision making are needed more than ever before. All these and many others are needed to improve our disaster risk reduction capacity.

b. Effective partnership between research centers and technology seekers is a must. The three pillars; farmers, extension agents and researchers must closely work to test and promote new crop varieties, as well as to teach management measures [2].

c. A major strategic element in supporting agriculture's role is information. The three pillars of mitigation are information, education, and technology transfer. 
d. Agricultural extension in its forms; public and private, as well as advisory services can play a significant role in providing farmers with the needed information, education and technologies, on how to cope with climate change through adaptation and mitigation measures.

e. Extension systems can help farmers deal with climate change through adaptation and contingency measures that deal with what cannot be prevented.

f. Extension systems can assist farmers and preparing them for greater climate variability and uncertainty, especially in providing advice on how to deal with new insects, weeds and diseases, dealing with droughts and avoiding floods.

g. Extension staff can help farmers with knowledge, proper practices and management systems that are resilient to climate change implications such as no till (Zero Tillage), sequential cropping, intercropping, etc.

\section{References}

1. Nelson G, Rosegrant M, Ko J, Robertson R, Sulser T, et al. (2010) Climate Change: Impact on Agriculture and Costs of Adaptation. IFPRI Washington DC.

2. Davis K (2009) Agriculture and Climate Change: An Agenda for Negotiation in Copenhagen For Food, Agriculture, and the Environment the Important Role of Extension Systems Focus 16 Brief 11.

3. World Bank (2013) Disaster Risk Reduction through Climate Change Adaptation.

4. Farajalla N (2013) Major Climate Change Projections for the Arab World.

5. IRIN Humanitarian news and analysis (2012). Climate Change: In the Arab world, building fridges to live in an oven.

6. Karas J (2006). Climate change and the Mediterranean Region.

7. Abdel Hamid M AR (2009). "Climate Change in the Arab World, Threats and Responses. In "Troubled Waters, Climate Change, Hydro politics, and Transboundary Resources".

8. Aljazeera (2013). Refugee influx worsens Jordan's water woes.

9. IFRC and CRED (2010). Climate Change Conference: Climate change facts and figures.

10. Asian Development Bank (2014). Facts \& Figures. Climate Change in Asia and the Pacific.

11. Madhava Sarma and Durwood Zaelke (2009). State of the world 2009. Climate connection.

12. Stern, NH (2007) The Economics of Climate Change: The Stern Review. Cambridge, UK; New York: Cambridge University Press.

13. Cline, WR (2007) Global Warming and Agriculture: Impact Estimates by Country (Washington DC: Center for Global Development: Peterson Institute for International Economics).

14. World Bank (2008) Report.

15. Alrusheidat J (2006) Cultural Dimensions of Technology Transfer. Journal of Food. Agriculture and Environment 4.

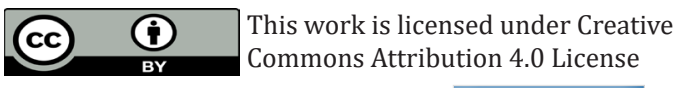

To Submit Your Article Click Here: Submit Article

DOI: 10.32474/OAJESS.2018.01.000105

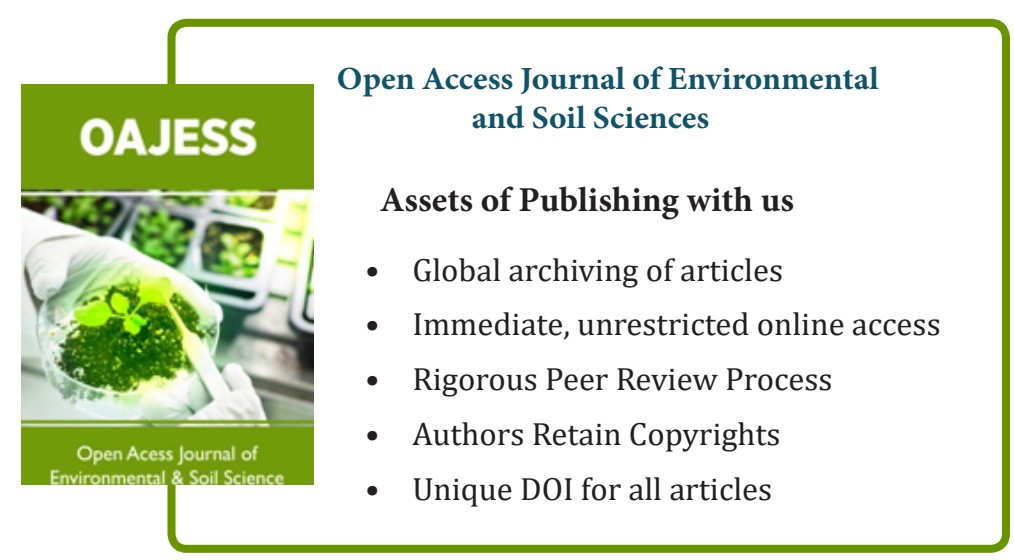

